\title{
Research with children: a philosophical, rights-based approach
}

\begin{abstract}
Much has been written in recent years about research methods used when conducting research with and about children, with many approaches taking cognisance of the children's rights agenda. This article proposes adopting a philosophical approach, through Community of Philosophical Inquiry (CoPI), as a research method that pays attention to children's rights. In so advocating, the argument presented is that CoPI makes explicit children's conceptual understanding and that this complements other research methods. CoPI allows for authentic voice and 'conceptual autonomy' through the shared meaning-making in philosophical dialogue by recognising children's capacities as thinkers in their own right.
\end{abstract}

Keywords: research methods; Philosophy with Children; children's rights; children's voice

\section{Introduction}

Philosophy with Children $(\mathrm{PwC})$ was created as a pedagogical approach rather than as a research method. Since its inception it has promoted recognition of children's capacities as thinkers in their own right, made visible through joint meaning-making and the conceptual engineering typically seen in philosophical dialogues (Lipman, 2003). Amongst the different approaches to PwC, Community of Philosophical Inquiry (CoPI), a particular technique for conducting a philosophical dialogue, deploys a number of specific features that make it particularly appropriate to address children's rights, notably in relation to voice and participation, in the area of educational and other social science research. Through CoPI children have conceptual autonomy and a means for collaborating. These specific features support the claim that it may be used as a rights-based research method, providing a valuable 
addition to the methods available in the field of research with children. In this article, we will defend this claim by describing the unique structure of CoPI based on studies where we have used it as an empirical research tool (Conrad, Cassidy, and Mathis 2015; Cassidy, Conrad et al. 2017; Conrad, Mathis, and Cassidy et al. 2018).

Pascal and Bertram (2014) note that significant reconsideration of research and practice is needed to ensure that children can enjoy the rights afforded them by the United Nations Convention on the Rights of the Child (UNCRC) (United Nations, 1989) and that the reframing of this research and practice should be 'inclusive, participatory and action focused' (272). Taking Lundy's (2007) four elements of space, voice, audience and influence as important in advancing children's participation, we argue that CoPI offers a unique insight into children's thinking as it allows us to understand the process of their joint meaningmaking during the dialogue. More specifically, it reveals their conceptual explorations as they analyse and reason for different, possibly contrasting, interpretations of key concepts. The dialogue is also inclusive in nature, providing opportunities for children's authentic voices.

The aim of this article is to present CoPI as one approach to rights-based research methods, particularly with children. It does not aim to provide a review of research methods, but draws on issues within the field, making reference to relevant literature throughout the article, to support the case for the inclusion and consideration of what CoPI might add to an already impressive, growing and innovative discipline. The article acknowledges the need for specific research methods with children and describes the practice of CoPI before considering CoPI as a research method that addresses issues in research relating to children's voice. To be clear, CoPI is not being proposed as an alternative, but as an addition, to the toolkit of research methods because of its particular structure and the philosophical dimension of the dialogue. 


\section{Situating Community of Philosophical Inquiry}

Involving children in research acknowledges their agency (Beazley et al. 2009) and that they are 'capable of making productive contributions towards increasing our understanding not only of their own lifeworlds but also of society as a whole' (Hanson 2015, 427). This resonates strongly with the research literature pertaining to Childhood Studies where questions of children's status as less than full members of society is challenged (Matthews 1982, 2008; James, Jenks and Prout 1998; Kennedy 2006; Qvortrup 2006; Cassidy 2012). Acknowledging children's status and agency are particularly significant within research methods, notably with respect to taking a rights-based approach (Lundy et al., 2011; Lundy and McEvoy 2012; Wall 2017; Blaisdell et al. 2018). Agency implies that children have capacity and that they are able to articulate views that require them to be listened to. CoPI, when used as a research method, is situated within these fields, where children are recognised as members of society who are rights-holders with agency and who have something to say.

The issue of how to reflect this stance when doing research with children continues to evolve, with Horgan (2017) acknowledging challenges in finding appropriate research methods with children. Indeed, Hammersley (2017), for example, is concerned that there is a risk that children will be guilty of 'recycling and reworking... adult talk' (120), questioning, perhaps their capacities and implying that adults never regurgitate perspectives of friends, family, colleagues or what they have read in the media when asked for their views, emphasising that children are deficit in some way (Matthews 2008). There have, however, been attempts to equalise the research process by advancing approaches that situate adults and children on a more level playing field, with Horgan (2017) identifying that some approaches advocate the researcher involves herself more closely in the children's lives by being more 'childlike', engaging in the children's play or by not adopting the privileged adult status and authority 
role. However, Mayall (2000) would dispute that this is possible since in some approaches, such as research interviews, generational differences cannot be ignored.

This may lead one may to suggest that there is a need to adapt methods in order for them be used with children, and increasingly this is the case (see, for example, Wall, Higgins, Hall, and Gascoine 2017). While research methods may not need to 'move, unsettle or provoke' (Semenec 2018, 64) their participants, engagement with the inquiry and process is desirable. Prout (2000) is clear, however, that rather than a specific approach to research with children, an approach that carefully applies techniques that allow research participants' contexts to be taken into account is required; this may include the fact that the participants are children. $\mathrm{He}$ asserts that good research methods are needed rather than those specifically for children. It is with respect to this suggestion that CoPI is proposed as a research method.

\section{Philosophy with Children}

Philosophy with Children (PwC) is the generic name given to all forms of practical philosophy undertaken with children (Cassidy 2007; Gregory, Haynes, and Murris 2017).

All derive from Matthew Lipman's original Philosophy for Children (P4C) programme created in in the 1970s (Lipman, Sharp and Oscanyan 1980; Lipman 2003; Pardales and Girod 2006; McCall 2009; Vansieleghem and Kennedy 2011). While academic philosophy tends to focus on learning about the history of ideas, the approach generally found in universities (Gazzard 1996; Murris 2000), PwC encourages participants to engage in dialogue about philosophical questions. Through using everyday language it invites participants to scrutinise ideas, issues and topics of concern such as freedom, happiness, God, etc., not in order to find right or wrong answers, but to question and elucidate the concepts and understand the fundamental nature of things. 
The various approaches to $\mathrm{PwC}$ have certain elements in common as they all provide a rational and critical inquiry into the most basic principles of the world and our understanding of it (see, for example, Lipman 2003; Gregory, Haynes and Murris 2017), but the focus here is on McCall's CoPI (Cassidy 2007; McCall 2009) because of some particular features of CoPI to which we return later.

CoPI sessions usually involve anywhere between eight and thirty participants and in various contexts such as schools, kindergartens, prisons, libraries, youth clubs, etc., with dialogues generally lasting up to an hour. Simply put, CoPI adheres to the following structure:

- Participants sit in a circle in order that they can see one another;

- A stimulus, usually a short story, poem, image or news item, is read aloud by either the participants or the facilitator, depending on participants' reading ability;

- Participants ask questions provoked by the stimulus and one is chosen for consideration;

- If participants wish to contribute they raise their hand and when called to speak by the facilitator they begin by saying, 'I agree/disagree with [name] because...';

- They may not use technical language or jargon in their contribution;

- They may not refer to an authority such as a book, a television programme or a teacher as their reason for their agreement/disagreement; and

- There is no search for consensus or conclusion.

Questions asked by the children range across a wide variety of topics; they may, for instance, explore whether there is an end to space, if people should be paid the same regardless of the job they do, if graffiti might be considered to be art, if someone received a head transplant would they still be the same person, and so on, depending on the initial stimulus. These 
questions are philosophical as they invite reasons regarding certain possibilities and impossibilities, which elucidate the concepts involved (space, just allocation, identity, art).

To give a sense of a CoPI dialogue, an excerpt from a transcript where CoPI was used as a research method is presented below (see Cassidy, Conrad et al., 2017) (figure 1). It is taken from the first seven minutes of the session. The children, aged ten, were asked, following an initial short story, whether they would take a pill to make them an adult instantly. Note that the facilitator selects each speaker from those who have indicated by raising their hand that they have something to contribute, but these interventions (the calling on a child by name) have been redacted due to word limit constraints; only her interventions that seek clarification have been retained. The children's names have been anonymised. 
Kate: If she got that pill she wouldn't be able to have more responsibilities, she would have more responsibilities but maybe not handle them very well. Like, for instance, if she was having a conversation like why do children wear school uniforms, she would probably be speaking as a child, though she's taken the pill to be like an adult, but she might have the voices of a child.

Alan: I disagree because if you're a child you won't know as much as you would know as an adult, so you wouldn't know your numbers or how to pay bills and stuff like that.

Theo: I disagree with Alan but agree with Kate because if you become an adult you'll miss out on your whole childhood; you won't be able to enjoy being free from all the adult responsibilities.

Facilitator: Say a wee bit more about that.

Theo: So, adults have to do taxes, they have to worry about money, but children just get to relax, play with their friends. Adults don't get to do that too often.

Kevin: I sort of disagree with Theo because if you were a kid, most the things have to do with rules. So if you're an adult, adults wouldn't be able to have fun as much as kids, but at least they get to decide what they do and they have their own rules that they can do and they can break their own rules as much as they want, like let's say if they were on a strict diet, they can get as many cheat days as they want. That's what my mum does. Every day.

Natalie: I agree with Kevin because, yeh, kids do have a lot of rules, whereas when you're an adult you can do what you want really, but unless it's really bad and then the police might take you away.

Facilitator: Give an example of a rule that children have to stick to.

Mary: No violence.

Melanie: I disagree with Theo because most times adults do go out and play with their friends, not just... not play, but go out with their friends and do something with them.

Johnny: I disagree with Mary because violence isn't usually... even if an adult made their own rules, they'd be able to do violent stuff, they wouldn't be able to do that because if they go out in the street and this guy says hi to them and starts talking to them, being friendly; see if you went and hit him, he would call the police because that isn't allowed. Or either, he would start a fight and he would punch back and then somebody else would've seen you do that and phone the police no matter where.

Julie: I agree with Theo because when you, if you become an adult when you're a child, you wouldn't be able to have a happy childhood because you'd just go straight to adult and would have to deal with all their problems that they've got.

Tony: I agree with Alan because, say you were seven when you had the pill, you would miss out on most of your education; you wouldn't know a lot if you were an adult.

Kate: I agree with Kevin and Mary because most adults don't have to follow as many rules as children because children need to follow rules like wear certain clothes, you need to eat certain food, clean your room. As an adult you don't have many rules to follow. But it's not going to be as easy being an adult because there's a lot of childhood that you could've experienced like your thirteenth birthday which is a big deal and you're just not learning as much about things.

Facilitator: Why's you're thirteenth birthday a big deal?

Kate: Because you're turning into a teenager and you're still not an adult, so you're missing your years as a teenager and your years as an infant, kind of.

Facilitator: What's the difference between a teenager and the infant that you described, and the teenager and an adult?

Kate: A teenager is more, like when you get in high school, that's more of a teenager kind of stuff. Like, teenagers have more ability to go places but as a child you're not really able to go a lot of places yourself.

Sarah: I agree with Kate because you usually adults don't have many rules because adults make up rules for their children. So, it's like when they're older they don't need to do all of their rules because they've passed them on to the children to do.

dialogue's facilitator has responsibility for ensuring that the structure is maintained and that

the dialogue remains as philosophical as possible, partly in her juxtaposition of speakers and

partly through a series of possible interventions that seek clarity. She may ask, for example, 
'What do you mean by $x$ ?' or 'Can you say a little more about y?' or 'Can you give an example of z/not z?' or 'What is the distinction you're making between $p$ and q?'. These types of interventions occur uniformly in all dialogues, irrespective of the children's ages. They show the facilitator's limited means to intervene as she will not comment, evaluate, summarize or recapitulate any of the points presented by the children. And yet, these interventions requiring clarifications allow key concepts to be drawn out and require the children to elaborate upon their reasons to which other participants can respond. The subsequent reason-pattern that unfolds dynamically elucidates the children's thinking about the world. This pattern is clearly marked by the 'I agree/ disagree...because...' structure indicating consensus and controversy. This type of movement can be seen in the dialogue above, with the disagreement occurring at the beginning in relation to the extent taking the pill would allow one to adopt an adult stance in the world. Any philosophical dialogue aims at consensus and controversies supported by reasons, yet, with CoPI it is built into the structure used for the dialogue thereby allowing the facilitator to 'fade out' in this respect.

Despite this oppositional structure, the notion of shared meaning-making is central to CoPI, where participants work collaboratively to inquire into the question or topic at hand as they engage in a better understanding of the nuances of meaning inherent in the concepts being explored (Cassidy and Christie 2013). Again, the excerpt above makes this clear, where Julie makes the claim that missing out on childhood would mean having to assume responsibilities too early. The children philosophising attribute different epistemic stances to children and discuss whether adults' lives are determined exclusively by responsibilities. Each speaker builds on previous contributions, though participants need not make explicit reference to all the points that have shaped their thinking. Participants can state the extent to which they agree/disagree with previous statements (McCall 2009; McCall and Weijers 2017). 
Participants can choose to speak or not, and there is clear evidence of children who in other contexts are reticent, contributing enthusiastically in CoPI dialogues such as marginalised or bullied children (Cassidy, Christie et al. 2017; Cassidy et al. 2018). CoPI is essentially an egalitarian practice where all voices are welcome, where academic ability and age are no bar, and where children's status as people with something to contribute is recognised (Cassidy 2007).

\section{Voice}

Conrad et al. (2015) posit that there are few opportunities for children 'to experiment with their views, to try out their reasoning, to be listened to and to have their range of views considered carefully' (115), and that CoPI offers this. 'Voice' is used here because it is broader than an expression of views. It is the opportunity to explore, refine and articulate one's conceptual understanding of the world by seeking to identify the grounds for specific differences made through philosophical dialogue, allowing concepts and meaning to be unpacked. Semenec (2018) is correct to highlight the challenges inherent in speaking of voice or of giving others voice, that there is a danger that their experiences become fixed or preserved. However, a philosophical dialogue / philosophical approach allows for the exploration of ideas and participants' representation of the world rather than an investigation into experiences; this is what moves it to a philosophical rather than a narrative account and thus pointing to the particular value philosophical dialogue has when used as a research method. This is not to descry narrative accounts, but they differ from what may be produced during philosophical dialogues in that the participants and researchers are focused on concepts and ways in which these articulate with experiences and representations of the world rather than discussions being focused on personal accounts (Byrne, 2017). 
While Lundy (2007) asserts that 'voice is not enough', it is obviously a key component in research, whether with respect to sharing experiences, offering views and opinions, in making suggestions, or by asking questions. The extract above, for instance, shows that Natalie raises a question about the implications of a child (in the scenario) 'being smart'. This question introduces something to be considered in determining distinctions between adults and children and was returned to throughout the dialogue. This came directly from the children and necessarily so as the facilitator has no means to introduce this type of difference in the course of the dialogue. The problem in much of what we hear of children's views is that it is mediated and filtered by adults and this is often done in order to satisfy certain adult agendas (Bucknall 2014; Roberts 2000); the same can be true when conducting research (Byrne, 2017; Hammersley, 2017). The challenge, therefore, is in ensuring that what is heard is authentic; that, as far as possible, individuals' views are not excluded, and that children do not simply say what they think the researcher wants to hear or, as Horgan (2017) notes, that they replicate peers' comments, thereby presenting an incorrect or incomplete picture of which they are not the 'author'.

CoPI offers an opportunity to reveal children's understanding of issues. The structure requires that in making connections to previous contributions by agreeing/disagreeing and, more importantly, providing reason(s) for agreements/disagreements, participants cannot simply repeat a previous point (McCall 1991; McCall and Weijers 2017). Participants engage with one another in a discussion of problems as they emerge along the way and can introduce or concentrate on particular ideas that interest them. This can be seen above when the participants introduce to the dialogue the idea of rules and who determines these and who has to adhere to them, and later in the dialogue when the children draw a distinction between laws and rules. The CoPI structure does not allow the facilitator to follow her own agenda; she may only intervene to probe for clarification, for example, by asking, as in the instance 
above, "Give an example of a rule that children have to stick to" in order to invite the participant to extend his contribution when he stated that there are some rules that only children have to "stick to".

CoPI allows participants to interact freely with one another's ideas. None of the facilitator's interventions allow her to lead the participants to a desired response due to the limited means of intervening, though these means are sufficient to guarantee the philosophical nature of the dialogue. The inquiry belongs to the participants and the facilitator must follow their lead. Of course, this may mean that, used as a research method, there is the risk that the dialogue meanders in a direction that appears not to address the initial question, but the skill of the facilitator/researcher is in being able to follow the dialogue, allowing it to go in different directions, accepting that what will be offered is an insight into the children's thinking on the topic, for example when Kate draws a distinction between teenagers, adults and infants. Although the dialogue is structured by the facilitator, her focus, as noted previously, is on maintaining the integrity of the philosophy through her interventions and her selection of speakers in order to highlight potential opposing views expressed by the children, but not to contribute or comment on the content directly. This may situate the approach as different from other types of focus groups.

While other disciplines and approaches may shed light on children's general understanding, CoPI facilitates the exploration of concepts under interrogation as in the dialogue above in relation to the concepts of child and adult. For instance, in Horgan's (2017) study where she spoke with children and young people about the extent to which they had decision-making opportunities in their homes, schools and communities, she notes 'that the younger children perhaps did not fully understand the concept of "community" (254), an important concept in the study. She does not, however, write that she asked them about the concept and their use of it. In using a philosophical approach, the children would have a structure to explore what 
was meant by 'community'. In fact, it would necessarily require such consideration in order to count as philosophical. Consequently, this would facilitate the researcher's understanding of the children's conceptualisation of the term and, in turn, therefore, potentially afford a richer understanding of the children's responses. This goes beyond Bucknall's (2014) request that children be given opportunities to express their views through research. CoPI is inherently about sharing views, but at a level where the participants share more than their opinions or perspectives, they explore ideas regarding representations of the world and are doing so collaboratively. The extract above illustrates some of the explicit concepts that are interrogated throughout the dialogue such as rules and responsibility, but also concepts that are implied in what is said, for example, power and freedom. The children often identify key concepts in what they decide to address, for instance, concepts pertaining to rules, age and knowledge feature throughout this particular session, with notions of personal identity over time being introduced by the children twenty minutes into the dialogue.

Of course, there is the question of whose views are heard and the risk that they are not representative, giving air to only the most confident, most articulate or most dominant children (Bucknall 2014). CoPIs structure means that all participants have the opportunity to speak, should they choose. The facilitator selects speakers in an order that is likely to juxtapose the ideas in order to generate a forward momentum to the dialogue. This means that children who are more likely to dominate in other contexts do not have this opportunity in CoPI. This is confirmed in other studies, and is also illustrated in the extract above, where the analysis shows that participants link back to contributions from several speakers previous to their own, and also that some participants do not speak for a length of time, until they have something they wish to share (Cassidy and Christie 2013). The structure allows for a nonthreatening response in that the ideas are interrogated rather than a person having to defend a 
view and persuade others to that view. The structure also permits, and this is important, children to be silent should they so choose.

In discussing research methods that may be used with children there is concern that children are silenced (Lewis 2010). Spyrou (2016) addresses the over-simplification of voice to stress that researchers must attend to silences. Silence in CoPI does not presume that the silent child is not listening or thinking about the topic under discussion; for instance, Omar, in the dialogue from which the above extract is taken, did not volunteer a contribution until twentyfive minutes into the session. Systematic analyses of CoPI dialogues has shown that some participants do not volunteer a contribution until very late in the dialogue, while others in the class did not contribute at all (Cassidy, Christie et al. 2017; Cassidy et al. 2018). Silence should not be read to mean that the child is anxious, dominated, shy or has no views on the topic. It may be that the child does not want to contribute or participate in the dialogue or research and is exercising that privilege. This is different from Bucknall's (2014) concern, that the silent child is not confident enough 'to contradict the majority views of their peers' (76). There is no claim, here, that CoPI ensures confidence in children, but that care should be taken in how silence is construed or understood in CoPI. The structure of CoPI promotes contradiction, and these contradictions help dialogues to remain philosophical. While allowing space for participants to explore their ideas in a meaningful way, CoPI as a research method allows the exploration of children's ideas at a more conceptual, and arguably deeper level.

\section{Conceptual autonomy}

Byrne (2017) commends narrative inquiry as an opportunity to 'access... the students' thoughts, shared experience and discussions' (37). While narrative approaches are valuable, CoPI might augment this by focusing on the concepts and arguments used by children in 
relation to the topic being explored. The structure offered by CoPI allows participants to engage in dialogue that evolves to explore philosophically the concepts they are interested in and want to understand more deeply by reasoning for and against contrasting and alternative views. This is something that other approaches might not so easily access and that is inherent to the structure of CoPI. For instance, twenty minutes into the dialogue (above) a participant raises the problem of continuous personal identity. She is concerned that should the pill to become an adult be taken then she would not be recognised physically. The dialogue explores this idea but turns, too, to reflect on the extent to which one's physical appearance signifies one's identity and whether or not the 'adult' would be the same person as the one who took the pill.

Participants often use thought-experiments, examples, analogies, metaphors and hypotheses to express their ideas about the ultimate nature of existence, reality, knowledge and goodness (Cassidy and Christie 2013; Daniel 2007; Daniel and Auriac 2011). These allow participants to identify where there may be omissions, weaknesses or strengths in the ideas and arguments presented. It is through the range of conceptual possibilities that Kellett (2014), in discussing the importance of children's rights and research into their lives, notes that it is important that 'a clear, discursive space has been delineated for children and young people' (24). CoPI may be said to offer this space by bringing participants together. This may also satisfy Lundy's (2007) requirement of space as necessary in facilitating children's voice.

It is important, asserts Hammersley (2017), that if we wish to claim that children are autonomous then we have to be clear about what it is they are free from or what it is they are free to do. In proposing CoPI as a research method, one claim would be that children are free to express their thinking and reasoning on a particular topic without the researcher determining the direction of the dialogue, as mentioned above, and that differences and divergent thinking in participants' contributions are exposed. This can be seen when Kate 
agrees with Kevin and Mary that "adults don't have to follow as many rules as children" but she extends this to consider the impact of adults' experiences, with Sarah following this later by suggesting that "adults make up rules for their children". Sarah's contribution takes the point further by introducing power dynamics in the adult/child relationship which is addressed further in the session.

Hanson (2015) asserts that if we are serious in wishing to see children's views accurately represented they ought to have 'conceptual autonomy'. This, he says, involves adult researchers in 'continuously questioning our interpretations of children's ideas as well as of the analytical frameworks and conceptual tools that inform power struggles over definition' (430). Returning to analysis later, questioning and interpreting participants' ideas is inherent in the use of CoPI. The structure and interventions available to the facilitator and participants allow contributions to be interrogated as part of the dialogue. Importantly, the children work with concepts throughout the dialogue and they, in their agreements/disagreements and reason-giving, provide definitions and clarity on the points being made. The facilitator does not translate the dialogue or infer meaning but the dialogue as a whole allows us to see the entire thread that has led to a particular point and subsequent points. CoPI allows participants to explore concepts autonomously. It supposes that children have the capacity to engage on a conceptual, philosophical level, a key assumption of PwC (Daniel and Auriac 2011; Lipman 2003; McCall 1991).

\section{Capacity}

Opening or closing opportunities for children to engage in research often hinges on translation of the phrase 'is capable of' under Article 12 of the UNCRC (Kellett 2014). Notably, Article 12 provides for all children to air their views freely; the notion of capacity pertains to the second part of the statement, that such views carry certain weight depending 
on the child's age and maturity. Much literature relating to engaging children in and with research revolves around questions of age and/or capacity. Smith (2011) argues that research methods that assume children's competence and foreground children's perspectives are much needed. While research in the area of child development increasingly points to what children are capable of, we need to be mindful of views that present children as incompetent or deficient in comparison to adults, notably in terms of their rational capacities or ability to understand others' perspectives (Author1 2007; Hammersley 2017; Matthews 1994). For example, Horgan (2017) posits that research methods that are engaging and that 'enable the abstract [to] become concrete' (253) should be promoted. Like Hanson, Lundy et al. (2011) suggest that children of around five years-old 'find it difficult to think beyond their own immediate experience...[or] find it difficult to focus on the issue, and their contributions can be inappropriate or lack relevance' (731). Indeed, they go on to propose that children 'will not always be able to express a reasonable, informed view on every issue that affects them' (732). While this may be true, the same can be said of many adults in relation to matters of economics, domestic or foreign policy or other social issues.

PwC clearly opposes to this view on empirical grounds (Matthews 1994, 2008), and CoPI, as one approach, illustrates children's capacity to engage with abstract ideas in a meaningful way to address particular types of research questions. Its structure supports children to offer views, take on others' perspectives, make connections across contributions, and provide justifications for the ideas and perspectives presented (See, for example, Matthews 1982; Daniel 2007; Daniel and Auriac 2011; McCall and Weijers 2017). This runs somewhat counter to Scott's (2000) suggestion that 'less structured methods of interviewing are more appropriate for younger children' (101). The nature of CoPI, regardless of whether we take it as a research method or pedagogy, counters this view due to the philosophical content the dialogues expose, thereby clearly situating itself against certain assumptions about methods 
suitable for doing research with young children. Indeed, PwC generally, and CoPI specifically, is facilitated with children as young as four who engage in structured but freeflowing dialogue (e.g. Cassidy, Conrad et al. 2017; Conrad et al. 2015; McCall 1991; Daniel and Auriac 2011).

\section{Collaboration}

CoPI participants work together to create meaning, though not necessarily agreement (Cassidy and Christie 2014). As becomes clear in the extract cited above, participants explore ideas together, scrutinise core concepts raised with regard to these and air a range of alternative perspectives that are interrogated, discarded, maintained and offered for further consideration, as illustrated above. Group interviews need not require participants make connections across the contributions, though they may, but CoPI demands it necessarily. It allows children to work together across a wide range of different levels of competences or abilities in a way that is inclusive of all. The strength of focus group interviews is recognised by Flewitt (2014) in terms of opening areas of inquiry and allowing the researcher to hear something of the participants' views and experiences. However, CoPI offers an insight into why certain views are prevalent by considering the conceptual understanding emerging from the dialogue. Importantly, participants are likely to explore a range of ideas that other dialogic approaches such as interviews might not allow, the focus being philosophical in nature and thus addressing the fundamental nature of the world. Further, the participants inquire together and strive for understanding, supported by the facilitator when asking for clarification. In CoPI support comes from within the group; the participants must collaborate in their search for meaning and understanding.

Research in $\mathrm{PwC}$ demonstrates how children collaborate to create meaning (See, for example, Cassidy and Christie 2013; Colom et al. 2014; Topping and Trickey 2007). Mayall (2000) 
recognises what dialogue with children when undertaking research might allow: listening to one another; taking account of others' contributions and replying to them; adding to others' points; and so on. This is built into CoPI. In addition, philosophical dialogue requires the presentation of ideas, exploration of concepts, offering of examples, provision of reasons, connections between perspectives and the desire to seek agreement and disagreement. Conversation, though rich, need not contain these elements.

\section{Rights}

Situating rights at the centre of research with children might allow a shift in the balance of power (Lundy et al. 2011; Beazley et al. 2009), enabling children to be seen as rights holders, ensuring that due attention is paid to their voice. 'Giving children a voice' in research projects is problematic since the gift tends to reside with the adult who also controls what is discussed or explored in the study (Bucknall 2014). In research contexts where adults conduct research with and about children, the power relationships must be acknowledged and the negative effects these might have should be minimised.

Beazley et al. (2009) discuss notions of power and note that 'Powerful adults construct 'the child', but powerless children are unable to construct 'the [equally genderless] adult' (367). In CoPI children are supported by the structure to construct whichever concepts they choose, and however they choose. It affords participants power that they may not have in other contexts because they are able to direct the dialogue and be explicit about their definition of terms. Interestingly, the children in the project (Cassidy, Conrad et al. 2017) on children's philosophical considerations of childhood constructed notions of adulthood across the groups, and this was because they raised the concept and interrogated it amongst themselves. It would be foolish to suggest the researcher rescinds all power because, at least at the outset, she proposes the focus for the inquiry; she presents the stimulus or question to provoke the dialogue, but the turn the dialogue takes resides with the participants, thereby diminishing the 
facilitator's power somewhat in relation to the content of the dialogue (see, for example, Bartels, Onstenk and Veugelers 2016; Cassidy 2016). This does not, though, rule out children raising questions within the dialogue or proposing questions in collaboration with the researcher if participatory approaches are to be fostered. What is hoped is that the topic will be engaging enough for the children to consider, that they will see it as relevant and important in their lives, such as the sixteen year-old participants who explored whether or not one can ever be truly free when discussing notions of citizenship (Cassidy and Christie 2014). There are certain elements, such as those noted above, that allow CoPI to be described as rights-informed research method. While the children need not determine the purpose of the project or be involved in the analysis and subsequent dissemination (Horgan 2017; Lundy et al. 2011), it is through philosophical dialogue that children take possession of their world, name it, question it, challenge it and shape it. Additionally, the silence children may choose in CoPI demonstrates that the research, as all research with children should, respects children's rights, particularly to privacy, while simultaneously promoting their rights (Lundy and McEvoy 2012). By using additional methods or in recognising, as in other approaches, the limits to what is presented, researchers obviate the bias potentially evident as a consequence of silent participants' views not being aired.

It is important that the researcher can demonstrate that 'the research has the potential to enhance the well-being of participants' (Smith 2011, 17), including that the voices have influence (Lundy 2007). Cassidy (2016) asserts that PwC is an appropriate approach to advancing children's citizenship and their human rights, but as a research methods it also offers something that 'cultivates minds which think freely from existing power relations' (Kim 2017, 94). CoPI supports Lundy et al.'s (2011) view that the 'challenge of any UNCRC-informed approach to children's participation is ensuring that children's views are taken seriously' (730). It offers participants the opportunity to reflect on issues they raise as 
they exercise their right of expression. CoPI, as an approach to research, facilitates children's thinking and expression, and is considered emancipatory and participative in this regard. Further, the authenticity of children's voice in CoPI lends credibility to the potential influence these voices may have.

\section{Analysis}

While CoPI is not appropriate if one wants to quantify how much exercise children undertake or the ways in which they use their mobile phones, it affords an insight into their thinking and reasoning about issues or concepts that can augment evidence gathered by other means such as surveys, observations, experiments, drawings or other visual methods. Children may, for example, explore the purpose or role of technology, such as mobile phones, in their lives or they may reflect on what they think is important in terms of friendships or discuss the kind of society in which they want to live through philosophical dialogue. This is not to say that other approaches do not explore such topics, but the essence of CoPI is that the topics are interrogated philosophically.

Research using CoPI to-date has used a grounded theory approach to analysis. In analysing a CoPI transcript, or an audio recording, it is easy to see the direction of the dialogue. For example, in the dialogue from which the extract above is taken, the participants work between concepts of rules while also exploring notions of education, violence and responsibility. In following the structure of 'I agree/disagree with...' patterns can be drawn through the session and other dialogues associated with a project. Areas of interest are obvious, as are areas of conceptual challenge. For example, Johnny, above, introduces a challenge to Mary's notion of rule-breaking with Maureen, later in the dialogue 'agreeing and disagreeing with Johnny at the same time' to make a further distinction that advances the importance of age in the scenario being depicted. 
Importantly, too, dynamics within the dialogue and between the participants are also evident; a key element in researching with groups (Parker and Tritter 2006). Participants work between concepts, explore related notions, weighing their interpretation by means of examples and counter-examples provided or thought experiments suggested in order to contrast a present situation by an alternative that promotes understanding. For example, when asked in what kind of society the children would like to live, the groups engaged in the study, in the two countries concerned, repeatedly introduced a thought experiment of a society where everything is free, reflecting on positive elements and eventual problems that could arise under such circumstances (Conrad et al. 2015, Conrad et al. 2018). The uniformity of the same thought experiment may come as a surprise, but throughout the different studies where CoPI has been used as a research method, despite some differences, core concepts have been regularly addressed regardless of whether the dialogue took place in Scotland, Switzerland, Brazil or China, and this allowed us to analyse the data gathered. This draws on an important feature when using CoPI as a research method. In following the 'I agree/disagree with...because...' structure, reasoning patterns can be drawn on in addition to the concepts introduced to defend particular perspectives. Areas of interest are obvious, as are areas of conceptual challenge. Further, as Spyrou (2016) suggests, what is not said in a dialogue is also important, for example, the younger children in one study (Conrad et al. 2015) did not consider voting rights while the fifteen year-olds introduced this. Such silences or omissions may helpfully be analysed.

Beazley et al. (2009) offer principles for ensuring children's rights to be properly researched are taken into account. Two in particular resonate particularly strongly in proposing CoPI as a rights-based research method: 'children's perspectives and opinions must be integral to research; Methods need to be found, and used, to help children to express their perspectives and opinions freely' (370). Further, by engaging directly with a particular question and 
sharing ideas in the group, there is less risk of 'restorying' (Byrne 2017), where the researcher interprets or restates what participants say. In CoPI the researcher does not need to interpret what is meant by certain words, phrases, terms or ideas because this happens as part of the dialogue. Participants present views and make connections between the ideas explicit by following the structure and offering their own examples to illustrate the points they make, meaning that participants' views are arguably more authentic.

Participants, in directing the dialogue, may stray from the original question and explore other issues that arise through the course of the dialogue. The researcher should be skilled enough to recognise that this may be illuminative and discuss in her work why the focus shifted, noting what is important about what was said in relation to the original question.

In CoPI, participants need not provide their own opinions; they are engaged in experimenting with and exploring ideas rather than trying to persuade individuals to their point of view to 'win' an argument. This offers scope to consider the range of ideas children present and how these are situated against others. Bearing in mind the pitfall of participants saying what they think the researcher wants to hear, CoPI allows a range of views to be heard. It may be the perspectives themselves that are important in exploring some research problems rather than ascribing views to particular individuals. In philosophical dialogue, the participants and/or the facilitator probe the contributions for meaning. This is important if children are, for example, considering the purpose of schooling rather than their own experiences of school. This is not to say that children will not discuss their experiences of schooling during a dialogue on such a topic, but they can explore what schooling is for without doing so. For example, they may discuss indoctrination as the purpose of schooling without (knowingly) having experienced it. Information about children's experiences of schooling can easily be accessed in other ways. It is the conceptual, philosophical perspective that is accessed through CoPI. 
In CoPI there is no search for conclusions or consensus at the end of a dialogue. Generally this rule is observed so that participants recognise that questions remain. If researchers need to have a definitive conclusion or answer to the initial question, they can follow-up the dialogue with additional activities that provide them with this information. Indeed, the dialogue may open up avenues for further investigation through other methods or CoPI may follow from these.

\section{Limitations}

What is being proposed here, using CoPI as a rights-based research method, is new. This, therefore, means that it requires further use and reflection in order to gauge more fully its success given some of its features. CoPI is generally a practice that is undertaken over time (McCall 2009; Cassidy and Christie 2014), so without a skilled facilitator a group inexperienced in CoPI will find it more challenging to engage quickly with the philosophical. Additionally, the role of the facilitator and researcher is a complex one since the facilitator's loyalty is always to maintaining the philosophical dimension of the dialogue (McCall and Weijers 2017) while researchers, on the other hand, tend to be able to ask questions of their own devising or to pull participants back to a topic or idea that may be of interest to their study. This creates something of a tension for the researcher who is also the facilitator. Given that participants need not address the question initially posed and that they can set the direction of the dialogue, this is a challenge for the researcher, as discussed above. Indeed, this openness may raise questions for some research ethics committees because there are concerns as to where the children might direct their contributions. As in other methods, researchers cannot be certain of the topics that may arise, but assurances are given to ethics committees - and participants - that participants need not provide personal experiences to exemplify their points, and that the facilitator would, using the range of interventions available to her, shift the dialogue should it become clear that participants are sharing 
personal detail that suggests they are at risk. She would then follow recognised procedures for following-up any such contribution. No topic, however, is out of bounds in CoPI (Chetty and Suissa 2017), but in using CoPI the dialogue should remain on a philosophical level rather than one designed to promote dialogue around personal experiences.

Further, in using CoPI, a decision would have to be made whether to retain the rule that participants need not give their own opinions. This rule may make it more challenging to ascertain whether the perspectives presented belong to the participants or if it is more helpful to the research to have a philosophical reflection on a topic rather than being able to ascribe specific perspectives to specific individuals or groups. In order to use CoPI the aim of the research would have to be on a topic that requires a philosophical exploration. Given that other approaches do not demand this, this seeming limitation may be one of its strengths, however. This element is also relevant when considering that using CoPI will not lead participants to a decided conclusion. Researchers would have to be content that they are, as in other approaches, being offered a snapshot of views at a particular time, and that these are not final and may even be hypothetical. These potential limitations, though, are also part of the richness afforded by employing a philosophical approach in research methods.

\section{Conclusion}

Horgan (2017) urges us to focus on 'critical reflexive representation' (p.250) which demands that we consider the processes adopted in facilitating children's voices. This, she says, requires that influences from society, culture, institutions and ideologies are taken into account, but so too are the power dynamics in terms of 'how children's voices are heard and represented' (250). She is correct in emphasising that 'we cannot eradicate power inequities in research with children' (256), but that the inequities ought to be acknowledged and minimised. CoPI as a research method has something to offer here. It is a specific form of 
group discussion, employing particular features which are somewhat different to some of those currently used within research methods. These very features engage the children intellectually and lead to sustained, shared thinking amongst participants because the philosophical dimension of the dialogue enhances the quality of reasoning and conceptual clarity (Hildebrandt et al. 2016). It can, therefore, potentially complement other approaches, producing in-depth insights into children's thinking, reasoning and understanding. It recognises children as beings with the capacity to think, reason, engage and have views on the world and their experiences in it. It provides the space, audience and opportunity for voice required by Lundy (2007), but it does this by removing, as far as possible, 'the lens of adultist assumptions' (Roberts 2000, 55) by enabling children to speak for and between themselves.

In advancing CoPI as a research method, the suggestion is that it is a practice which can be used to drive the research; it is child-led in that the facilitator must follow the direction the children take, something of which Gallacher and Gallagher (2008) may approve when advocating approaches that allow for unpredictability over predetermined techniques. While CoPI is a pre-determined technique, it is unequivocally open in terms of adopting the 'methodological attitude' (Gallacher and Gallagher 2008, 513, italics in original) that allows for wide-ranging responses. Kim (2017) asks where the emphasis lies in adopting a pedagogical approach and cautions that 'linking children's research directly with inquirybased learning or learner-centred education seems inappropriate, and pursuing it mainly for its pedagogical benefits may obscure what research is fundamentally for' (89; italics in the original). Research is an inquiry - whether initiated by children or adults, together or separately - and philosophical inquiry offers a complementary approach. Certainly, $\mathrm{PwC}$ is a pedagogy, one in which emancipation is often seen as key (Cassidy 2007; Kohan 2018), but research should also focus on empowerment, whether it is about making schools better, 
improving health or garnering information to influence policy to enhance people's lives. This leads to Lundy's (2007) fourth feature that is necessary if children's voices are to be heard: influence.

If children are to be empowered through research and if pedagogy has a similar focus, then the potential for influence and impact may be increased, and we might see 'child and youth voice beginning to pervade policy and practice' (Kellett 2014, 28). Of course, this demands that children are engaged with the questions being asked. If there is to be influence as a consequence of children's voice, then 'listening well to children can make a difference to our understanding of their priorities, interests and concerns' (Clark 2014, 273). CoPI offers one approach that allows us to 'listen well'. To be clear, as Qvortrup (2000) says, 'there are many ways of collecting information about children's lives and childhood. No one method alone can produce all knowledge needed' (78). Like Semenec's (2018) use of contemporary art to engage children to become 'investigators of their own social and material worlds' (73) CoPI enables children to explore concepts and ideas pertinent to their social and material worlds, and to extend this beyond their immediate context. With its links to pedagogy, CoPI participants can move beyond knowledge generation to consider ideas that impact on their lives. CoPI has been little used as a research method, but it has much to offer in facilitating children's voices and affording insights into children's conceptual thinking and understanding of the world and their experiences. Further research studies using philosophical dialogue to gather data are required to gauge the extent to which an approach such as CoPI might usefully be employed as a rights-based research method.

\section{Acknowledgements}

The authors would like to acknowledge the Children's Voices on Childhood Project (see Cassidy, Conrad et al. 2017) of which this article is part. We would also like to acknowledge 
the very supportive discussions with Prof. Laura Lundy who prompted the writing of this article. We also thank the reviewers for their constructive comments.

\section{Funding}

This research received no specific grant from any funding agency in the public, commercial, or not-for-profit sectors.

\section{References}

Bartels R. Onstenk J and W Veugelers. 2016. "Philosophy for Democracy." Compare: A Journal of Comparative and International Education 46 (5): 681-700. doi: 10.1080/03057925.2015.1041367.

Beazley H, S. Bessell, J. Ennew and R. Waterson. 2009. “The Right to be Properly Researched: Research with Children in a Messy, Real World." Children's Geographies 7 (4): 365-378. doi: 10.1080/14733280903234428.

Blaisdell, C., L. Arnott, K. Wall and C. Robinson. 2018. “Look Who’s Talking: Using Creative, Playful Arts-based Methods in Research with Young Children.” Journal of Early Childhood Research.

Bucknall, S. 2014. "Doing Qualitative Research with Children and Young People." In Understanding Research with Children and Young People, edited by A. Clark, R. Flewitt, M. Hammersley, and M. Robb, 69-84. London: Sage. 
Byrne, G. 2017. 'Narrative Inquiry and the Problem of Representation: 'Giving Voice', Making Meaning.” International Journal of Research \& Method in Education 40 (1): 36-52. doi: 10.1080/1743727X.2015.1034097.

Cassidy, C. 2007. Thinking Children. London Continuum.

Cassidy, C. 2012. "Questioning Children.” Thinking: the Journal of Philosophy for Children 20 (1\&2): 62-68.

Cassidy, C. 2016. "Promoting Human Rights Through Philosophy with Children." International Journal of Children's Rights 24 (3): 499-521. doi: 10.1163/1571818202403001

Cassidy, C., and D. Christie. 2013. "Philosophy with Children: Talking, Thinking and Learning Together." Early Child Development and Care 183 (8): 1072-1083. doi: 10.1080/03004430.2013.773509.

Cassidy, C., and D. Christie. 2014. "Community of Philosophical Inquiry: Citizenship in the Classroom." Childhood \& Philosophy 10 (19): 33-54.

Cassidy, C., D. Christie, H. Marwick, L. Deeney, G. McLean, and K. Rogers. 2017. "Fostering Citizenship in Marginalised Children Through Participation in Community of 
Philosophical Inquiry.” Education, Citizenship and Social Justice 13 (2): 120-132. doi: $10.1177 / 1746197917700151$.

Cassidy, C., S-J. Conrad, M-F. Daniel, D. Garside, W. Kohan, K. Murris, M. Rego, X. Wu, and T. Zhelyazkova. 2017. "Being Children: Children's Voices on Childhood.” International Journal of Children's Rights 24 (3-4): 698-715. doi: 10.1163/15718182-02503006

Cassidy, C., H. Marwick, L. Deeney, and G. McLean. 2018. "Philosophy with Children, Selfregulation and Engaged Participation for Children with Emotional-behavioural and Social Communication Difficulties.” Emotional and Behavioural Difficulties 23 (1): 81-96. doi: org/10.1080/13632752.2017.1388654

Chetty, D., and J. Suissa. 2017. “"No Go Areas' - Racism and Discomfort in the Community of Inquiry." In The Routledge Handbook of Philosophy for Children, edited by M.R. Gregory, J. Haynes, and K. Murris, 11-18. London: Routledge.

Clark, A. 2014. "Developing and Adapting the Mosaic Approach.” In Understanding Research with Children and Young People, edited by A. Clark, R. Flewitt, M. Hammersley, and M. Robb, 200-209. London: Sage.

Colom, R., F.G. Moriyón, C. Magro, and E. Morilla. 2014. “The Long-term Impact of Philosophy for Children: A Longitudinal Study (Preliminary Results).” Analytic Teaching and Philosophical Praxis 35 (1): 50-56. 
Conrad, S-J., C. Cassidy, and C. Mathis. 2015. “Encouraging and Supporting Children's Voices." In Youth Quotas and Other Efficient Forms of Youth Participation in Ageing Democracies, edited by J. Tremmel, A. Mason, I. Dimitrijoski and P. Godli. Cham: Springer.

Conrad, S-J., C. Mathis, and C. Cassidy. 2018. "Philosophieren mit Kindern ist aktive Demokratie.” In Politische Bildung in der Demokratie. Interdisziplinäre Perspektiven, edited by B. Ziegler and M. Waldis. Wiesbaden, Germany: Springer.

Daniel, M-F. 2007. "Epistemological and Educational Presuppositions of P4C: From Critical Dialogue to Dialogical Critical Thinking." Gifted Education International 22 (2-3):135-147. doi: $10.1177 / 026142940702200305$.

Daniel, M-F., and E. Auriac. 2011. "Philosophy, Critical Thinking and Philosophy for Children.” Educational Philosophy and Theory 43 (5):415-435. doi: 10.1111/j.14695812.2008.00483.x.

Flewitt, R. 2014. “Interviews.” In Understanding Research with Children and Young People, edited by A. Clark, R. Flewitt, M. Hammersley, and M. Robb M., 136-153. London: Sage.

Gallacher, L-A., and M. Gallagher. 2008. "Methodological Immaturity in Childhood Research? Thinking Through 'Participatory Methods'.” Childhood 15 (4):499-516. doi: $10.1177 / 0907568208091672$. 
Gazzard, A. 1996. "Philosophy for Children and the Discipline of Philosophy." Thinking: the Journal of Philosophy for Children 12 (4): 9-16.

Gregory, M.R., J. Haynes, and K. Murris. 2017. "Philosophy for Children: An Educational and Philosophical Movement." In The Routledge Handbook of Philosophy for Children, edited by M.R. Gregory, J. Haynes, and K. Murris K., xxi-xxxi. London: Routledge.

Hammersley, M. 2017. “Childhood Studies: a Sustainable Paradigm?” Childhood 24 (1): 113-127. doi: 10.1177/0907568216631399.

Hanson, K. 2015. "International Legal Procedures and Children's Conceptual Autonomy.” Childhood 22 (4): 427-431. doi: 10.1177/0907568215609209.

Hildebrandt, E., and S. Campana. 2016. «Partizipation im alltäglichen Unterricht durch Kooperation und Individualisierung in heterogenen Klassen - ein Beitrag zur Demokratiebildung?» International Dialogues on Education: Past and Present 3 (3): 140 149.

Horgan, D. 2017. "Child Participatory Research Methods: Attempts to go 'Deeper'.” Childhood 24 (2): 245-259. doi: 10.1177/0907568216647787.

James, A., C. Jenks, and A. Prout. 1998. Theorizing Childhood. Cambridge: Polity Press. 
Kellett, M. 2014. "Images of Childhood and Their Influence on Research." In Understanding Research with Children and Young People, edited by A. Clark, R. Flewitt, M. Hammersley, and M. Robb, 15-33. London: Sage.

Kenndy, D. 2006. The Well of Being. Childhood, Subjectivity, and Education. Albany, New York: SUNY Press.

Kim, C-Y. 2017. "Participation or Pedagogy? Ambiguities and Tensions Surrounding the Facilitation of Children as Researchers." Childhood 24 (1): 84-98. doi: $10.1177 / 0907568216643146$

Kohan, W.O. 2018. "Paulo Freire and Philosophy for Children: A Critical Dialogue." Studies in Philosophy and Education. doi: 10.1007/s11217-018-9613-8.

Lewis, A. 2010. "Silence in the Context of 'Child Voice'." Children \& Society 24 (1): 14-23. doi: 10.1111/j.1099-0860.2008.00200.x.

Lipman, M. 2003. Thinking in Education (2 ${ }^{\text {nd }}$ edition). Cambridge, Mass: Cambridge University Press.

Lipman, M., A.M. Sharp, and F.S. Oscanyan. 1980. Philosophy in the Classroom. Philadelphia, PA: Temple University Press.

Lundy, L. 2007. “'Voice' is Not Enough: Conceptualising Article 12 of the United Nations Convention on the Rights of the Child." British Educational Research Journal 33 (6): $927-$ 942. doi: $10.1080 / 01411920701657033$. 
Lundy, M., and L. McEvoy. 2012. "Childhood, the United Nations Convention on the Rights of the Child, and Research: What Constitutes a 'Rights-based' Approach?” In Law and Childhood Studies: Current Legal Issues Volume 14, edited by M. Freeman. Oxford: Oxford University Press.

Lundy, L., L. McEvoy, and B. Byrne. 2011. "Working with Young Children as Coresearchers: An Approach Informed by the United Nations Convention on the Rights of the Child." Early Education \& Development 22 (5): 714-736. doi:

$10.1080 / 10409289.2011 .596463$.

McCall, C. 1991. Stevenson Lectures on Citizenship. Glasgow: Glasgow University Press.

McCall, C. 2009. Transforming Thinking. Philosophical Inquiry in the Primary and Secondary Classroom. London: Routledge.

McCall, C., and E. Weijers. 2017. "Back to Basics: A Philosophical Analysis of Philosophy in Philosophy with Children." In The Routledge Handbook of Philosophy for Children, edited by M.R. Gregory, J. Haynes, and K. Murris, 83-92. London: Routledge.

Matthews, G.B. 1982. Philosophy and the Young Child. Cambridge, Mass: Harvard University Press.

Matthews, G.B. 1994. The Philosophy of Childhood. Cambridge, Mass: Harvard University Press. 
Matthews, G.B. 2008. “Getting Beyond the Deficit Conception of Childhood: Thinking Philosophically With Children.” In Philosophy in Schools, edited by M. Hand and C. Winstanley, 27-40. London: Continuum.

Mayall, B. 2000. “Conversations with Children. Working with Generational Issues.” In Research with Children. Perspectives and Practices, edited by P. Christensen, and A. James, 120-135. London: FalmerPress.

Murris, K. 2000. “Can Children do Philosophy?” Journal of Philosophy of Education 34 (2): 261-279. doi: 10.1111/1467-9752.00172.

Pardales, M.J., and M. Girod. 2006. "Community of Inquiry: its Past and Present Future." Educational Philosophy and Theory 38 (3): 229-309. doi: 10.1111/j.14695812.2006.00196.x.

Parker, A., and J. Tritter. 2006. "Focus Group Method and Methodology: Current Practice and Recent Debate." International Journal of Research \& Method in Education 29 (1): 2337. doi: $10.1080 / 01406720500537304$.

Pascal, C., and T. Bertram. 2014. "Transformative Dialogue: The Impact of Participatory Research on Practice.” In Understanding Research with Children and Young People, edited by A. Clark, R. Flewitt, M. Hammersley, and M. Robb, 269-284. London: Sage. 
Prout, A. 2000. "Foreward." In Research with Children. Perspectives and Practices, edited by P. Christensen, and A. James, xi-xii. London: FalmerPress.

Qvortrup, J. 2000. “Macroanalysis of Childhood.” In Research with Children. Perspectives and Practices, edited by P. Christensen, and A. James, 77-97. London: FalmerPress.

Qvortrup, J. (2006). “Are children subjects or a liability?” Childhood 13 (4): 435-439. doi: $10.1177 / 0907568206068555$

Roberts, H. 2000. "Listening to Children: And Hearing Them." In Research with Children. Perspectives and Practices, edited by P. Christensen, and A. James, 225-240. London: FalmerPress.

Scott, J. 2000. “Children as Respondents. The Challenge for Qualitative Methods.” In Research with Children. Perspectives and Practices, edited by P. Christensen, and A. James, 98-119. London: FalmerPress.

Semenec, P. 2018. "Re-imagining Research with Children Through an Engagement with Contemporary Art." Childhood 25 (1): 63-77. doi: 10.1177/0907568217718033.

Smith, A.B. 2011. “Respecting Children's Rights and Agency. Theoretical Insights Into Ethical Research Procedures." In Researching Young Children's Perspectives. Debating the Ethics and Dilemmas of Educational Research with Children, edited by D. Harcourt, B. Perry, and T. Waller, 11-25. Abingdon, Oxon: Routledge. 
Spyrou, S. 2016. “Researching Children's Silences: Exploring the Fullness of Voice in Childhood Research.” Childhood 23 (1): 7-21. doi: 10.1177/0907568215571618.

Topping, K.J., and S. Trickey. 2007. “Collaborative Philosophical Inquiry for School Children Cognitive Gains at 2-year Follow-up.” British Journal of Educational Psychology 77 (4): 787-796. doi: 10.1348/000709907X193032.

United Nations. (1989). United Nations Convention on the Rights of the Child. Geneva: United Nation.

Vansieleghem, N., and D. Kennedy. 2011. "What is Philosophy for Children, What is Philosophy with Children - After Matthew Lipman?” Journal of Philosophy of Education 45 (2): 171-182. doi: 10.1111/j.1467-9752.2011.00801.x.

Wall, K. 2017. "Exploring the Ethical Issues Related to Visual methodology When Including Young Children's Voice in Wider Research Samples International Journal of Inclusive Education 21 (3):316-331. doi: 10.1080/13603116.2016.1260845.

Wall. K., S. Higgins, E. Hall, and L. Gascoine. 2017. "What Does Learning Look Like? Using Cartoon Story Boards to Investigate Student Perceptions (from 4 to 15) of Learning Something New." In Good Questions: Creative Collaborations with Kids, edited by M. Emme, and A. Kirova, 1-21. Thunder Bay. 